\title{
Intercultural Sensitivity, Gender, And Nationality Of Third Culture Kids Attending An International High School
}

Antonio Morales, QSI International School of Shenzhen, China

\begin{abstract}
Due to the globalization and interconnectedness of people from different cultures, intercultural competence is a prerequisite to communicating effectively across different cultures. The Intercultural Sensitivity Inventory (ICSI) measures a person's ability to modify behavior in culturally appropriate ways when coming into contact with diverse cultures. The ICSI is a measurement based on the concepts of individualism and collectivism. The majority of research on intercultural competence and intercultural sensitivity (ICS) has primarily focused on adult populations in business, international education exchange programs, and adult third culture kids (ATCKs). However, such research involving high school students attending an international school outside of the United States is scant. The purpose of this quantitative study was to examine the differences in intercultural sensitivity (ICS) among Third Culture Kids (TCKs). Specifically, this study assessed the differences in ICS among the independent variables of gender and participant's passport country. Additionally, the study examined the difference in ICS between Korean females and non-Korean females. The ICSI was used to measure the participants' ICS. The sample consists of 139 international high school students. The independent samples t-test revealed no statistically significant in ICS among males and females, as well as Korean females and non-Korean females. However, the results revealed a statistically significant difference between Korean and non-Korean students. Korean students scored lowered on the ICSI than their counterparts.
\end{abstract}

Keywords: Third Culture Kids (TCKs); International Schools; Intercultural Sensitivity; Intercultural Sensitivity Inventory (ICSI)

\section{INTRODUCTION}

n 2011, the Association of Americans Resident Overseas reported that 5.08 million Americans lived in over 160 countries throughout the world (Bates, 2013). However, Americans are not the only nationals migrating to other countries. A recent UN study (2013) revealed that that 232 million people, or 3.2
percent, of the world's population live outside their home country. As expatriates migrate to different areas of the globe, their children accompany them and attend international schools (Mackenzie, Hayden, \& Thompson, 2003). As a result of this migration, there is a unique multicultural subgroup emerging- Third Culture Kids (TCKs). According to Inman, Ngoubene-Atioky, Ladany, and Mack (2009), due to the multinational nature of the student body, international schools are increasingly challenged by a transient and mobile family lifestyle, competing cultural practices, political upheavals, and limited personnel and professional resources. In spite of this competing and transient lifestyle, students have to assimilate into their new schools and learn the hierarchal values in their international schools. Students who have spent a significant portion of their formative years outside of their home countries are TCKs (Pollock \& Van Reken, 2001).

The purpose of this quantitative study was to examine the differences between the levels of intercultural sensitivity (ICS) among international high school students as measured by the Intercultural Sensitivity Inventory (ICSI) of Third Culture Kids (TCKs). In addition, this study also seeks to examine whether there is a significant difference in the levels of ICS between Korean females and non-Korean females. International students attending an international school experience cultural differences on a daily basis and as they continue to attend international schools, their competence in intercultural relations should increase over time. The ICSI will be used to quantify the level of intercultural sensitivity of high school students. The participants are students at an international school located in a 
Southeast Asian City. The independent variables are gender and nationality. The dependent variable will be generally defined as intercultural sensitivity (ICS), the person's ability to discriminate and experience relevant cultural differences (Hammer et al., 2003).

The importance of focusing on intercultural communication and becoming culturally competent is relevant and important for international projects, organizations, and companies. Recently, there has been an increase in international efforts in improving intercultural communication and the "harmonization of human relationships" by organizations such as UNESCO Convention on Protection and Promotion of the Diversity of Cultural Expression (Ferri, 2005; Pauwelyn, 2005), the EU, the UN, the Islamic Declaration on cultural Diversity ISESCO (2004), the Council of Europe (2008) (Zarzu, 2013, p. 201). Educational organizations, too, are focusing on cultural democracy and global citizenship (Covert, 2013; Taylor, 2013; Taylor, 2014; Yu, 2012).

\section{REVIEW OF THE LITERATURE}

\section{Intercultural Competence}

As the world continues to become increasingly globally interconnected and nations throughout the world are increasingly becoming multicultural, cross-cultural research is increasing (Fail et al., 2004; Gilbert, 2008; Hoersting \& Jenkins, 2011; van der Zee \& van Oudenhoven, 2013). Empirical research has reported that people who have been exposed to multiple cultures, such as TCKs, have the ability to function and communicate appropriately in a given culture by switching their cultural lens (Hong et al., 2003; LaFromboise et al., 1993; Song, 2009; Vivero \& Jenkins, 1999). Consequently, exposing children to different cultures, norm, and behaviors promotes less ethnocentric attitudes and behaviors, and greater intercultural efficiency (Vivero \& Jenkins, 1999).

One specific challenge TCKs face is that of intercultural competence. Intercultural competence is "the ability to function effectively in another culture" (Gertsen, 1990, p. 341). Moving from one culture to another entails an adjustment period (Black, Mendenhall, \& Oddou, 1991); consequently, researchers have developed theories that illustrate and explain the process of intercultural competence, such as Adler (1975) and Oberg (1960).

Research in intercultural competence has warranted the development of many models that describe the movement of individual's ethnocentric view to an ethnorelative one (Bennett, 1986). Furthermore, recent studies have been conducted examining factors that influence intercultural development (Chocce et al., 2015; Holm, Nokelainen, \& Tirri, 2009; Straffon, 2003; Williams, 2005; Yashima, 2010). Bhawuk and Brislin (1992) proposed the Intercultural Sensitivity Inventory (ICSI) that measures the cultural constructs of individualism, collectivism, and flexibility and open-mindedness. The purpose of the ICSI is to explore cultural identity through the examination one's own cultural value orientations and flexibility in adapting to new cultures and persons (Landis, Bennett, \& Bennett, 2003). Therefore, the ICSI was the instrument used for this study.

\section{Hofstede's Cultural Dimension}

Hofstede (1980), a prominent researcher on culture, developed four cultural patterns or dimensions as a result of his study of 150,000 individuals around the world: (1) power distance (PDI), (2) individualism (IDV)(3) masculinity (MAS) and (4) uncertainty avoidance (UAI) . In his study, Hofstede used constructed scaled indices to rank each nation within the dimension thereby achieving a 'typology' of natural and cultural differences; this led him to posit that the four dimensions he had identified shaped behaviors in different social settings, including education (Signorini, Wiesemes, \& Murphy, 2009).

The first dimension, power distance, states that there exist large differentials of power and consequently, distances exist between people with various levels of authority (hierarchal) and roles are established. This hierarchal power structure is more evident is large power distance (LPD) countries, such is the case of East European, Latin, Asian, and African countries (Hofstede, Hofstede, \& Minkov, 2010).

The second dimension, individualism, reflects the way members of a group emphasize their own needs over their ingroup's need. Hofstede's concept of "in-group" is used to differentiate collective nations from individualist ones 
(Signorini et al., 2009). In individualist nations, according to Hofstede (1980), the individual tends to be more independent from their group, and seeking his or her individual interests and goals is acceptable. In collectivist nations, on the other hand, the group's interest and goals are primary and supersede the individual's interest.

Masculinity/femininity does not refer to gender inequalities, but rather, it focuses on differentiation on the basis of activity. For example, masculine cultures focus on earnings, advancements, and assertiveness at work. In contract, feminine cultures seek personal relationship goals such as getting along with coworkers and superiors and working in friendly environments. Hofstede (2011) asserts that the masculinity versus femininity dimension "refers to the distribution of roles between the genders...men's values from one country to another contain a dimension from very assertive and competitive and maximally different form women's values on the one side, to modest and caring and similar to women's values on the other.

Uncertainty avoidance is the level of risk accepted by a culture, which can be gleaned from the emphasis on rule obedience, ritual behavior, and labor mobility (Straub et al., 2002). Uncertainty avoidance primarily focuses on the extent a culture programs its members to feel either comfortable or uncomfortable in unstructured situations. Uncertainty avoidance cultures try to minimize the possibility of unstructured situations by creating "strict behavioral codes, law, and rules, disapproval of deviant opinions, and a belief in absolute Truth; 'there can only be one Truth and we have it"” (Hofstede, 2011, p. 10).

\section{Third Culture Kids (TCKs)}

In 1963, the Useems pioneered the research on internationally mobile kids and adolescents who have lives outside their home country or country of citizenship during their developmental years by coining the term third culture kid (Useem, Useem, \& Donoghue, 1963). The Useems were in India studying missionaries, educators, businesspeople, and other foreign workers (Pollock \& Van Reken, 2001; Useem, Useem, \& Donoghue, 1963). The Useems called the community created by the expatriates "third culture"; the first culture characterized the parents' country of origin and the second culture was the host country. The third culture is the amalgamation of the first and second culture. The Useems and Donoghue's (1963) research served as the catalyst for future research of internationally mobile children (Chapman, 1975; Dewaele \& Van Oudenhaven, 2009; Fail, 1996; Gillies, 1998; Lee, Bain, \& McCallum, 2007; McLachlan, 2007; Stuart, 1980; Useem, Useem, \& Donoghue, 1963; Walters \& Auton-Cuff, 2009).

\section{International Schools}

The diversity of languages, customs, taboos, values, and perceptions is uniquely present in every international school, but every international school is uniquely different from other international schools. According to the International School Consultancy Group (ISC), it is predicted to see a significant increase of number of schools in 2014; the ISC indicates that there are now 7,017 international schools around the world that services the needs of over 3.5 million students. As the number of international schools has increased, efforts in defining and investigating the phenomenon of international schools also continues to increase (Hayden \& Thompson, 1995).

Hill (2002) described international schools as those "whose students and staff are representative of a number of cultural and ethnic origins, where the International Baccalaureate (IB) and/or a number of different national courses and examinations are offered and where the ethos is one of internationalism as distinct from nationalism" (pp. 7-8). Despite the various definitions of international schools, Hill's definition will serve as the platform from which this paper will spring in discussing international schools. As Hill (2002) suggested, international schools are made up of a number of various cultural and ethnic origins. This multicultural cornucopia that characterizes international schools environment permits students, parents, faculty, and staff to interact and communicate cross-culturally. International schools provide an environment with a "strong probability that the cultural development of their pupils will be influenced by the culture of the host country as well as the various cultures they collectively represent" (Langford, 2012, p. 29). 


\section{METHODS}

\section{Participants}

Table 1. Top ten nations represented in the study.

\begin{tabular}{l|c|c}
\hline \multicolumn{1}{c|}{ Nationality } & Frequency (n) & Percent \\
\hline Korea & 43 & 30.9 \\
\hline United States & 22 & 15.8 \\
\hline Taiwan & 11 & 7.9 \\
\hline Hong Kong & 10 & 7.1 \\
\hline Canada & 7 & 5 \\
\hline China & 5 & 3.6 \\
\hline India & 5 & 3.6 \\
\hline Japan & 5 & 3.6 \\
\hline Brazil & 4 & 2.9 \\
\hline Philippines & 4 & 2.9 \\
\hline Total & 116 & 83.3 \\
\hline
\end{tabular}

The participants in this study are high school students, grades 9-12 th grade, enrolled in an American-based, Middle States Accreditation (MSA) accredited school located in China. The participants of this study are third culture kids (TCKs). The school caters to expatriate's children. However, only those students who have spent three or more years in an international school were included in this sample. The sample consists of 82 males and 58 females ranging in age from 13 to 19 years old, 43 Koreans and 96 non-Koreans. They come from over 48 different countries. Table 1 lists, in order of frequency, the top ten countries of origin for students who participated in the study.

\section{Instrumentation}

The Intercultural Sensitivity Inventory (ICSI) (Bhawuk \& Brislin, 1992) was used to measure intercultural sensitivity, the dependent variable. The ICSI is a 46-item, theory-based instrument that will be made available to students online. The purpose of this instrument was to measure intercultural sensitivity. The ICSI was developed as a valid and reliable measure of intercultural sensitivity; specifically, the ICSI measures the cultural constructs of individualism, collectivism, and flexibility and open-mindedness (Bhawuk \& Brislin, 1992).

\section{Procedure}

Students at the school will be asked to take the ICSI paper survey in their English Language Arts (ELA) class because every student, regardless of their grade classification, is enrolled in an ELA class. The ICSI will take 30 to 45 minutes to complete. The researcher will administer the assessment. Also, students will complete a researcher-designed demographic survey. The demographic form will ask students to report their age, nationality, time spent in an international school, and their gender. Only those students who have attended an international school for at least three years (TCKs) will be included in the study. The students who do not return their forms will remain in class working on class work. Due to the block scheduling of the school, the administration of the ICSI will occur over two consecutive days.

The ICSI assessment is made available to all students involved in the study via paper copies. The ICSI data will be recorded and tracked via Excel software. In order to ensure students are TCKs, the researcher will confirm their response of time spent in an international school on the demographic questionnaire by confirming with the registrar office's records. The demographic questionnaire will require students to provide their names. If it is discovered that a student has not attended an international school for at least 3 years, his or her ICSI results were discarded. Then, the completed demographic surveys and ICSI scores were processed in an Excel spreadsheet for initial analysis. From Excel, the ICSI results were uploaded to Statistical Package for the Social Sciences (SPSS) for analysis. 


\section{RESULTS}

Research Question 1: Do males and females significantly differ on their level of intercultural sensitivity, as measured by the Intercultural Sensitivity Inventory (ICSI)?

An independent samples t-test was conducted to compare the ICS of men and women. Data screening included examining histograms of each data set for normality of distribution, creating boxplots to test for extreme outliers, and Levene's Test of equality of error for variance. There were no outliers, as assessed by inspection of a boxplot. The ICS scores for each level of gender were normally distributed, as assessed by Shipiro-Wilks test $(\mathrm{p}>.05)$. Homogeneity of variance was not violated $(\mathrm{p}=.77)$. There was not a significant difference in ICSI scores for male $(M=4.63, S D=.47)$ and female $(M=4.61, S D=.40), t(137)=.29, \mathrm{p}=.77, \mathrm{~d}=.05$. The $\mathrm{p}$ value is .77 and this value is greater than .05 . Therefore, we can conclude that the results regarding the first research question showed no statistically significant difference between male and female intercultural sensitivity. Table 2 depicts the Group Descriptive Statistics. Table 3 depicts the Independent Samples Test conducted for gender and intercultural sensitivity.

Table 2. Descriptive Statistics for Male and Female

\begin{tabular}{l|l|c|c|c|c}
\hline & Gender & N & Mean & Standard Deviation & Std. Error Mean \\
\hline \multirow{2}{*}{ ICSI } & Male & 81 & 4.63 & .47 & .05 \\
\hline & Female & 58 & 4.61 & .40 & .05 \\
\hline
\end{tabular}

Table 3. Independent Samples Test for Gender

\begin{tabular}{l|c|c|c|c|c}
\hline & T & Df & Sig. (2-tailed) & Mean Difference & Std. Error Difference \\
\hline ICSI & .299 & 137 & .766 & .023 & .077 \\
\hline
\end{tabular}

Research Question 2: Do international high school students' nationality significantly differ on their level of intercultural sensitivity, as measured by the ICSI?

An independent-samples $t$ test was conducted to compare the ICS of Korean and non-Korean students. Data screening included examining histograms of each data set for normality of distribution, creating boxplots to test for extreme outliers, and Levene's Test of equality of error for variance. There were no outliers, as assessed by inspection of a boxplot. The ICS scores for each level of gender were normally distributed, as assessed by Shipiro-Wilks test ( $\mathrm{p}>$ $.05)$. Homogeneity of variance was not violated $(\mathrm{p}=.01)$. There was a significant difference in ICSI scores for Korean students $(M=4.48, S D=.41)$ and non-Korean students $(M=4.68, S D=.44), t(137)=-2.52, p=.01, \mathrm{~d}=$ 0.43 . Cohen's effect size value $(\mathrm{d}=-.43)$ suggest a low practical significance. The $\mathrm{p}$ value is .01 and this value is less than .05 . Therefore, the results suggest that nationality, Korean and non-Korean, does statistically affect student's intercultural sensitivity. The researcher rejected the null hypothesis that there is no significant difference in ICS, as measured by the ICSI, among international high school students of various nationalities. In this study, non-Korean students had greater intercultural sensitivity than Korean students. Tables 4 and 5 depict the Group Descriptive Statistics and the Independent Samples Test, respectively.

Table 4. Descriptive Statistics

\begin{tabular}{l|l|c|c|c|c}
\hline & Nationality & N & Mean & Standard Deviation & Std. Error Mean \\
\hline ICSI & Korean & 43 & 4.48 & .41 & .06 \\
\hline & Non-Korean & 96 & 4.68 & .44 & .05 \\
\hline
\end{tabular}

Table 5. Independent Samples Test for Korean and non-Korean students

\begin{tabular}{l|c|c|c|c|c}
\hline & T & Df & Sig. (2-tailed) & Mean Difference & Std. Error Difference \\
\hline ICSI & -2.52 & 137 & .01 & -.21 & .08 \\
\hline
\end{tabular}


Research Question 3: Do Korean females and non-Korean females significantly differ on their level of intercultural sensitivity, as measured by the ICSI?

An independent-samples $t$ test was conducted to compare the ICS of Korean women and non-Korean women. Data screening included examining histograms of each data set for normality of distribution, creating boxplots to test for extreme outliers, and Levene's Test of equality of error for variance. There were no outliers, as assessed by inspection of a boxplot. The ICS scores for each level of Korean females and non-Korean females were normally distributed, as assessed by Shipiro-Wilks test $(\mathrm{p}>.05)$. Homogeneity of variance was not violated $(\mathrm{p}=.48)$. There was not a significant difference in ICSI scores for Korean females $(M=4.53, S D=.36)$ and non-Korean females $(M=4.63, S D$ $=.41), t(56)=-0.71, p=.48, \mathrm{~d}=-0.23$. The $\mathrm{p}$ value is .48 and this value is greater than .05 . Therefore, we can conclude that the results regarding the third research question showed no statistically significant difference between Korean females and non-Korean female intercultural sensitivity. The results do not allow the researcher to reject the null hypothesis that there is no statistically significant difference in ICS, as measured by the ICSI, between Korean females and non-Korean females. Tables 6 and 7 depict the Group Descriptive Statistics and Independent Samples Test, respectively.

Table 6. Descriptive Statistics for Korean Females and non-Korean Females.

\begin{tabular}{l|l|c|c|c|c}
\hline & Nationality & $\mathbf{N}$ & Mean & Standard Deviation & Std. Error Mean \\
\hline \multirow{2}{*}{ Female ICSI } & Korean & 12 & 4.53 & .36 & .10 \\
\hline & Non-Korean & 46 & 4.63 & .41 & .06 \\
\hline
\end{tabular}

Table 7. Independent Samples Test

\begin{tabular}{l|c|c|c|c|c|c}
\hline & T & Df & Sig. (2-tailed) & Mean Difference & Standard Deviation & Std. Error Difference \\
\hline Female ISCI &.-.71 & 56 & .48 & .09 & .077 & .13 \\
\hline
\end{tabular}

\section{CONCLUSION}

In 2011, the number of international students in the world was estimated to be well over 3.8 million (Banks \& Bhandari, 2012). The number of Third Culture Kids (TCKs) increases as the number of expatriates increases. The increasing number of TCKs affects the multicultural dynamics of international schools. Therefore, the ability to interact and communicate effectively within a diverse and multicultural environment is a necessary skill. Intercultural sensitivity (ICS) describes an individual's response to cultural differences and the perspectives of people from other cultures (Bhawuk \& Brislin, 1992). Research on intercultural competence and ICS has focused on adult population; however, there is scant research on international students, or TCKs.

This study assessed the difference in ICS of TCKs among the independent variables of gender and participant's passport country. The study revealed that there was no statistically significant difference between male and female students. However, it must be reported that males tended to score slightly higher than females. These findings are similar to McMurray's (2007) and Margarethe, Hannes, and Weisinger's (2012) results that reported no significant difference in ICS between males and females. McMurray (2007) examined potential disparities between levels of intercultural sensitivity among three groups of participants: international students, domestic students with international travel experience, and domestic students without international travel experience. Margarethe et al. (2012) explored the effects of intercultural education on business students. The researchers wanted to evaluate whether there is a difference in cultural sensitivity of students choosing two different business studies, one with, the other one without intercultural courses and inputs. Though, McMurray (2007) and Margarethe et al. (2012) noted that the female participants tended to score slightly higher than males.

Several studies have reported that females tend to exhibit higher ICS than their male counterparts (Fabregas et al., 2012; Holm, Nokelainen, \& Tirri, 2009; Ruiz-Bernardo, Ferrandez-Berrueco, \& Sales-Ciges, 2012; Westrick, 2004). Holm et al. (2009) examined the relationship between the ICS of Finnish 12-16 year old secondary school students and gender and academic achievement. Their results reported that the girls assessed their ICS higher than the boys did. Westrick (2004) also studied the relationship of gender on ICS and reported that females exhibited higher ICS than males. Other studies have attempted to identify predictive factors, such as gender- of ICS. Chocce et al. (2015) 
investigated many factors as predictive factors of ICS; gender was one of the factors. The study revealed that gender did not contribute significantly to ICS development. Altshuler et al. (2003) assessed the ICS of 24 physician trainees, 10 Americans and 14 non-Americans. The physicians had their intercultural sensitivity assessed, using the intercultural development inventory (IDI), before and after an intercultural training intervention. The results reported that post-training data showed that females exhibited higher levels of ICS than males. Altshuler et al.'s findings concurred with Fabregas et al. (2012) results, but Fabregas et al. stated that only gender could predict ICS.

The aforementioned studies were not in line with the current study in regards to gender and ICS. The difference could be attributed to the higher number of females from low uncertainty avoidance cultures. Although South Korea and Japan are characterized as high uncertainty avoidance dimensions, only 12 females in the study were South Korean and 2 were Japanese out of the 58 female participants involved in the study. Therefore, students who belong to cultures with higher uncertainty avoidance dimension may find it difficult to interact with peers from cultures characterized as lower uncertainty avoidance dimension.

The current study also investigated the difference in ICS based on nationality, specifically Korean and non-Korean students. According to the analysis of the data, there was a statistically significant difference between Korean and non-Korean students. Recent studies since 2010 have continued to investigate ICS based on nationality or country of origin and have reported that nationality does affect individual's ICS. Ruiz-Bernardo et al. (2012) investigated the difference in ICS based on gender, country of origin, educational background, and foreign language abilities. Their results reported that foreigners scored higher on ICS scale than locals. Ruiz-Bernardo et al.'s (2012) results support Lyttle, Barker, and Cornwell's (2011) study that concluded that people living in a country other than their nationality have significantly higher social sensitivity than local on monoculture people. Chocce et al. (2015) reported that nationality and having international friends were the predictive factors of ICS. The current study supports Chocce et al. (2015), Ruiz-Bernardo et al. (2012), and Lyttle et al.'s (2011) results that nationality affects an individual's intercultural sensitivity.

This study validated many studies that reported nationality as a factor affecting and individual's ICS (Chocce et al., 2015; Lyttle et al., 2011; Ruiz-Bernardo et al., 2012). As a result of this study, it is evident that an individual's nationality affects ICS levels and must be considered in the development of ICS. The Korean participants in this study reported a lower ICS score than their non-Korean counterparts. Korea is characterized as a high uncertainty avoidance and as such, they tend to minimize the possibility of unstructured situations by creating strict behavioral codes and intolerant of deviant persons and ideas; what is different is dangerous (Hofstede, 2011). The current study was conducted at an international high school where more than 40 nationalities are presents, with Koreans as the majority. Perhaps exploration of an individual's cultural dimensions and its effect on ICS is warranted.

The study did not report a significant difference in ICS between Korean and non-Korean females nor a significant difference between genders. However, many studies have reported that females appear to be more empathic than males (e.g. Eisenberg \& Fabes, 1998; Karniol, Gabay, \& Ochion, 1998; Zhou, Eisenber, Losoya, Fabes, Reiser, Guthrie, Murphy, Cumberland, \& Shepard, 2002). A closer look at empathy or other abilities and their potential to affect ICS is worth exploring.

\section{Recommendation for Future Study}

This is possibly the first study to be conducted with the Intercultural Sensitivity Inventory (ICSI) with international high school students, specifically Third Culture Kids (TCKs). The results supported the theoretical framework of the ICSI, individualism and collectivism constructs to measure intercultural sensitivity. Hofstede's dimensions are congruent with the results found in this study that relate to the level of ICS and nationality, specifically uncertainty avoidance and collectivism versus individualism dimensions. South Korea is considered a collectivist society. Also, South Korea is one of the most uncertainty avoiding countries in the world. The results of this study are congruent with collectivism versus individualism and uncertainty avoidance. Uncertainty avoidance indicates to what extent a culture programs its members to feel either uncomfortable or comfortable in unstructured situations. "Uncertainty avoiding cultures try to minimize the possibility of such situations by strict behavioral codes, laws and rules, disapproval of deviant opinions, and belief in absolute Truth" (Hofstede, 2011, p. 10). A Western-based international school encourages students to "think outside the box" and question "truths." This type of learning will conflict with 
Asian students' core beliefs. Furthermore, students from strong uncertainty avoidance countries may find it difficult to interact with peers from countries with weak uncertainty avoidance countries such as the United States, Australia, and Europe. It is suggested that if researchers are interested in measuring sensitivity, and if the cultures involved place a value on individualism or collectivism, they can consider using the ICSI. There are scant studies utilizing the ICSI.

Second, there have been similar studies that assessed international high school students' intercultural sensitivity, but not with the ICSI. Similar studies have used other instruments such as Bennett's Intercultural Development Inventory (IDI) and the Intercultural Sensitivity Scale Questionnaire (ICSSQ) (Straffon, 2003; Holm, Nokelainen, \& Tirri, 2009). Therefore, it is suggested that further research with this population be conducted in other international schools high schools in different countries for comparison.

The third area for further research involves the school leadership. Examining the ICS of teachers, counselors, and administrators who work with international students could help international schools create professional staff development that will raise awareness of the importance of ICS. Furthermore, determining the ICS of the staff will also inform the staff of their need to be culturally aware and sensitive of the various learning styles of their multicultural classroom. Teachers can create opportunities and lesson plans that foster intercultural competence. "All educators have both an ethical and professional responsibility to promote a safe and culturally competent school climate to support the holistic development of all students" (Limberg \& Lambie, 2011).

The fourth area for further research would involve a curriculum audit of international schools. International schools can use research about TCKs' ICS in creating curriculums that addresses, honors, and respects all cultures. Furthermore, teachers and administrators can create opportunities in curriculum development that will not only target knowledge base, but provide hands-on opportunities for students to interact with people from different cultures, such field trips to neighboring countries, collaborating with other neighboring international schools, and short-term study abroad programs.

This study highlighted differences in ICS between Korean and non-Korean participants and no difference in ICS between males and female students via quantitative measures. The quantitative nature of the study did not allow for a deeper understanding of the differences. Therefore, a similar mixed methods research study would provide additional statistical information that could possibly help explain the differences in ICS.

International schools have existed since the early 1900's, such as the International School of Geneva and Yokohama International schools that were both established in 1924 (Hayden \& Thompson, 1995). George Walker (2006), former head of the International Baccalaureate Organization (IBO) (2009), proclaimed that international education is an education for international-mindedness; an education designed to break down the barriers of race, religion and class; an education that extolled the benefits of cultural diversity; above all else, an education for peace. (p. 19)

IBO promotes global engagement, multilingualism, and intercultural understanding. Intercultural sensitivity is the ability to show sensitivity to the importance of cultural differences and to the points of view of people in other cultures (Bhawuk \& Brislin, 1992). The results of this study could inform how school administrators and teachers approach curriculum writing that will address the multicultural, pluralistic ideas and beliefs that characterize their class room; a multicultural curriculum can enhance the cultural aspects of communication, education, and values for socialization and interaction among their students.

The results of this study can inform how international schools approach teaching their international students. If the goal of the international school is to provide an education that embraces international-mindedness, then producing students who have a high level of ICS would be necessary. Having all students complete the ICSI would be one way to begin that process.

\section{AUTHOR BIOGRAPHY}

Dr. Antonio Morales is currently a high school teacher for Chavez High School located in Houston, Texas, United States of America. His area of study is Third Culture Kids (TCKs). He currently lives with his beautiful wife, Rachel, and son, Lucas, in Texas. Email: amorales1210@yahoo.com 


\section{REFERENCES}

Adler, P. S. (1975). The transitional experience: An alternative view of culture shock. Journal of Humanistic Psychology, 15, 13-23. Altshuler, L., Sussman, N. M., \& Kachur, E. (2003). Assessing changes in intercultural sensitivity among physician trainees using the intercultural development inventory. International Journal on Intercultural Relations, 27, 387-401.

Banks, M. \& Bhandari, R. (2012). Global student mobility. In D.K. Deardorff, H. de Wit, J. D. Hegle, \& T. Adams (Eds.), The Handbook of international higher education. Thousand Oaks, CA: Sage Publication Inc.

Bates, J. (2013). Administrator perceptions of transition programs in international schools.

Journal of Research in International Education, 12(1), 85-102. doi: 10.1177/1475240913478078.

Bennett, M. J. (1986). A developmental approach to training for intercultural sensitivity. International Journal of Intercultural Relations, 10(2), 179-196.

Bhawuk, D. P. S., \& Brislin, R. (1992). The measurement of intercultural sensitivity using the concepts of individualism and collectivism. International Journal of Intercultural Relations, 16, 413-436.

Black, J. S., Mendenhall, M., \& Oddou, G. (1991). Toward a comprehensive model of international adjustment: An integration of multiple theoretical perspectives. Academy of Management Review, 16(2), 291-317.

Chapman, J. M. (1975). Perceptions of culturally-racially mixed and non-mixed six-seven year old children in American dependents school of Okinawa (Order No. 7612413). Available from ProQuest Dissertations \& Theses Global. (UMI No. 288009044)

Chocce, J., Johnson, D. A., \& Yossatorn, Y. (2015). Predictive factors of freshmen's intercultural sensitivity. International Journal of Information and Education Technology, 5(10), 778-782. doi:http://dx.doi.org/10.7763/IJIET.2015.V5.610

Council of Europe. Committee of Ministers. (2008). White Paper on Intercultural Dialogue.

Covert, H. H. (2013). Stories of personal agency: Undergraduate students' perceptions of developing intercultural competence during a semester abroad in Chile. Journal of Studies in International Education, 18(2), 162-179.

Dewaele, J. M., \& Van Oudenhoven, J. P. (2009). The effect of multilingualism/multiculturalism on personality: No gain without pain for Third Culture Kids. International Journal of Multilingualism, 6(4), 443-459.

Eisenberg, N., \& Fabes, R. A. (1998). Prosocial development. In W. Damon (Series Ed.) and N. Eisenberg (Vol. Ed.), Handbook of child psychology: Vol. 3. Social, emotional, and personality development (5th ed., pp. 701-778). New York, NY: Wiley.

Fabregas, J. M. G., Kelsey, K., \& Robinson, S. (2012). Predicting intercultural sensitivity using demographic variables among college of agriculture undergraduate students. US-China Education Review, 8, 710-719.

Fail, H. (1996). Whatever Becomes of International School Students? International Schools Journal, 15(2), 31-36.

Fail, H., Thompson, J., \& Walker, G. (2004). Belonging, identity and Third Culture Kids Life histories of former international school students. Journal of Research in International Education, 3(3), 319-338.

Ferri, D. (2005). EU participation in the UNESCO convention on the protection and promotion of the diversity of cultural expressions: some constitutional remarks. European Diversity and Autonomy Papers EDAP, 3, 1-34.

Gertsen, M. C. (1990). Intercultural competence and expatriates. The International Journal of Human Resource Management, 1(3), 341362.

Gilbert, K. R. (2008). Loss and grief between and among cultures: The experience of third culture kids. Illness, Crisis, \& Loss, 16(2), 93109. Retrieved from http://ejournals.ebsco.com.ezproxy.liberty.edu:2048/direct.asp?ArticleID=46DAAB3AAB6101D17582

Gillies, W. D. (1998). Children third on the move culture kids. Childhood Education, 75(1), 36-38.

Hammer, M. R., Bennett, M. J., \& Wiseman, R. (2003). Measuring intercultural

sensitivity: The intercultural development inventory. International Journal of Intercultural Relations, 27(4), 421-443. Retrieved from http://dx.doi.org/10.1016/S0147-1767 (03)00032-4.

Hayden, M., \& Thompson, J. (1995). International schools and international education: A relationship reviewed. Oxford Review of Education, 21(3), 327-345.

Hill, I. (2002). The International Baccalaureate policy process in education. Journal of Research in International Education, 1(2), 183211.

Hoersting, R. C., \& Jenkins, S. R. (2011). No place to call home: Cultural homelessness, self-esteem and cross-cultural identities. International Journal of Intercultural Relations, 35(1), 17-30.

Hofstede, G. (1980). Culture's consequences: International differences in work-related values. Beverly Hills, CA: Sage.

Hofstede, G. (2011). Dimensionalizing cultures: The Hofstede model in context. Online Readings in Psychology and Culture, $2(1), 8$.

Hofstede, G., Hofstede, G. J., \& Minkov, M. (2010). Cultures and organizations: Software of the mind (3rd ed.). New York, NY: McGraw-Hill.

Holm, K., Nokelainen, P., \& Tirri, K. (2009). Relationship of gender and academic achievement

to Finnish students' intercultural sensitivity. High Ability Studies, 20(2), 187-200.

Hong, Y., Benet-Martinez, V., Chiu, C., \& Morris, M. W. (2003). Boundaries of cultural influence: Construct activation as a mechanism for cultural differences in social perception. Journal of Cross-Cultural Psychology, 34, 453-464

Inman, A. G., Ngoubene-atioky, A., Ladany, N., \& Mack, T. (2009). School counselors in

international school: Critical issues and challenges. International Journal for the Advancement of Counseling, 31(2), 80-99. doi:http:10.1007/s10447-009-9070-8

International Baccalaureate Organization (March 2009). Diploma programme: History guide. Cardiff, Wales.

Karniol, R., Gabay, R., Ochion, Y., \& Harari, Y. (1998). Is gender or gender-role orientation a better predictor of empathy in adolescence? Sex Roles, 39 (1-2), 45-59.

LaFromboise, T. D., Coleman, H. L. K., \& Gerton, J. (1993). Psychological impact of biculturalism: Evidence and theory. Psychological Bulletin, 114, 395-412. 
Landis, D., Bennett, J., \& Bennett, M. (2003). Handbook of intercultural training. Thousand Oaks, CA: Sage Publications.

Langford, M. (2012). Global nomads, third culture kids and international schools. International Education, Principles and Practice, 2843.

Lee, Y. J., Bain, S. K., \& McCallum, R. S. (2007). Improving creative problem-solving in a sample of third culture kids. School Psychology International, 28(4), 449-463.

Limberg, D., \& Lambie, G. (2011). Third culture kids: Implications for professional school counseling. Professional School Counseling, 15(1), 45-54.

Lyttle, A. D., Barker, G.G., \& Cornwell, T.L. (2011). Adept through adaptation: Third culture

individuals' interpersonal sensitivity. International Journal of Intercultural Relations, 35(5), 686-694. Retrieved from: http://dx.doi.org/10.1016/j.ijintrel.2011.02.015.

Mackenzie, P., Hayden, M., \& Thompson, J. (2003). Parental priorities in the selection of international schools. Oxford Review of Education, 29(3), 299-314.

Margarethe, U., Hannes, H., \& Wiesinger, S. (2012). An analysis of the differences in business students' intercultural sensitivity in two degree programmes. Literacy Information and Computer Education Journal, 3(3), 667-74.

McLachlan, D. A. (2007). Global nomads in an international school: Families in transition. Journal of Research in International Education, 6(2), 233-249.

McMurray, A. (2007). Measuring intercultural sensitivity of international and domestic college students: The impact of international travel. (Unpublished master's thesis), University of Florida, Florida, US.

Oberg, K. (1960). Culture shock: Adjustment to new cultural environment. Practical Anthropology, 7, 177-182.

Pauwelyn, J. (2005). The UNESCO Convention on cultural diversity, and the WTO: Diversity in international law-making. ASIL Insights, (15).

Pollock, D. C., \& Van Reken, R. (2001). Third culture kids: The experience of growing up among worlds. London, England: Nicholas Brealey.

Ruiz-Bernardo, R., Ferrandez-Berrueco, \& Sales-Ciges, M. (2012). Aplicación del modelo CIPP en el estudio de los factores que favorecen la sensibilidad intercultural. Relieve, 18(2), 1-14).

Signorini, P., Wiesemes, R., \& Murphy, R. (2009). Developing alternative frameworks for exploring intercultural learning: a critique of Hofstede's cultural difference model. Teaching in Higher Education, 14(3), 253-264.

Song, E. (2009). Coping with intercultural transactions in multicultural societies. Social Behavior and Personality, 37(2), $273-287$. Retrieved from http://search.proquest.com/docview/209871306?accountid=12085

Straffon, D. A. (2003). Assessing the intercultural sensitivity of high school students attending

an international school. International Journal of Intercultural Relations, 27, 487-501.

Straub, D., Loch, K., Evaristo, R., Karahanna, E., \& Srite, M. (2002). Toward a theory-based measurement of culture. Human Factors in Information Systems, 61-82.

Stuart, W. (1980). --What about Our Children: Third Culture Kids: Powerful Potential, Possible Pitfalls (Doctoral dissertation, IFCI Ministries).

Taylor, S. (2013). Globally-minded students: Defining, measuring and developing intercultural sensitivity. The International Schools Journal, 33(1), 65-75.

Taylor, S. (2014). Globally-minded students: Defining, measuring and developing intercultural sensitivity: Part 2. The International Schools Journal, 33(2), 26-34.

Useem, J., Useem, R., \& Donoghue, J. (1963). Men in the middle of the third culture: The roles of American and non-Western people in cross-cultural administration. Human Organization, 22(3), 169-179.

van der Zee, K., \& van Oudenhoven, J. P. (2013). Culture shock or challenge? The role of personality as a determinant of intercultural competence. Journal of Cross-Cultural Psychology, 44(6), 928-940.

Vivero, V. N., \& Jenkins, S. R. (1999). Existential hazards of the multicultural individual: Defining and understanding "cultural homelessness." Cultural Diversity and Ethnic Minority Psychology, 5(1), 6-26.

Walker, G (2006). Educating the global citizen. Suffolk, UK: John Catt Educational Ltd.

Walters, K. A., \& Auton-Cuff, F. P. (2009). A story to tell: The identity development of women growing up as third culture kids. Mental Health, Religion and Culture, 12(7), 755-772.

Westrick, J. (2004). The influence of service-learning on intercultural sensitivity: A quantitative

study. Journal of Research in International Education, 3(3), 277-299.

Williams, T. R. (2005). Exploring the impact of study abroad on students' intercultural communication skills: Adaptability and sensitivity. Journal of Studies in International Education, 9(4), 356-371.

Yashima, T. (2010). The effects of international volunteer work experiences on intercultural competence of Japanese youth. International Journal of Intercultural Relations, 34(3), 268-282.

$\mathrm{Yu}$, H. (2012). A study of engineering students' intercultural competence and its implications for teaching. Professional Communication, IEEE Transactions, 55(2), 185-201.

Zarzu, C. (2013). Who needs intercultural competences? Cross-Cultural Management Journal, 15(2), 197-203.

Zhou, Q., Eisenberg, N., Losoya, S. H., Fabes, R. A., Reiser, M., Guthrie, I. K., ... \& Shepard, S. A. (2002). The Relations of Parental Warmth and Positive Expressiveness to Children's Empathy-Related Responding and Social Functioning: A Longitudinal Study. Child development, 73(3), 893-915. 